\title{
Efecto del 2-aminoindano rigido, derivado del acenafteno, sobre la conducta estereotipada de ratas. Papel del sistema dopaminérgico cerebral.
}

\author{
Mariagracia Vera ${ }^{1}$, Ligia Angel ${ }^{1}$, Lucía Rodrígues ${ }^{1}$, Ana Cáceres ${ }^{1}$, José Ortega ${ }^{1}$, \\ Jaime Charris ${ }^{2}$, Anita Israel ${ }^{3}$, María Garrido ${ }^{3}$, Simón Lópes', Biagina Migliore ${ }^{1}$, \\ María Ramíres ${ }^{1}$ y Jorge Angel ${ }^{1}$ \\ ${ }^{1}$ Laboratorio de Síntesis Orgánica, Diseño y Evaluación Farmacológica de nuevos \\ productos. Departamento de Química, Facultad Experimental de Ciencias, Universidad \\ del Zulia, Maracaibo, Venezuela. \\ ${ }^{2}$ Laboratorio de Síntesis Orgánica, Facultad de Farmacia, Universidad Central de \\ Venezuela, Caracas, Venezuela. \\ ${ }^{3}$ Laboratorio de Neuropéptidos, Facultad de Farmacia, Universidad Central de Venezuela, \\ Caracas, Venezuela. \\ ${ }^{4}$ Department of Chemistry, University of Florida, Gainesville, Florida, USA. \\ Palabras clave: agonista dopaminérgico; profármaco; enfermedades neurodegenerativas; \\ Enfermedad de Parkinson.
}

Resumen. Las enfermedades neurodegenerativas y neuropsiquiátricas se encuentran directamente relacionadas con alteraciones o disfuncionalidad del sistema dopaminérgico central. Entre las primeras encontramos la enfermedad de Parkinson (EP), la disquinesia tardía, el síndrome de Tourette, la Corea de Huntington (EH), y entre las segundas la Esquizofrenia (EZ), la adicción, la manía, la depresión, y los desórdenes de la alimentación. Con el fin de contribuir con el arsenal terapéutico que permita restaurar la homeostasis de la neurotransmisión dopaminérgica central, se evaluó farmacológicamente el clorhidrato del 1-amino-6,7,8,8a-tetrahidroacenafteno 2 (Ja116a) mediante la cuantificación de sus efectos sobre la conducta estereotipada de ratas. Se emplearon ratas machos de la cepa Sprague-Dawley, a las que se les implantó una cánula intracerebroventricular (ICV). El compuesto 2 (Ja116a) fue administrado por vía ICV $(5 \mu \mathrm{g} / 5 \mu \mathrm{L}$ y $50 \mu \mathrm{g} / 5 \mu \mathrm{L})$, en presencia o ausencia de apomorfina (APO), haloperidol (HAL), buspirona (BUS) o ziprasidona (ZIP); o por vía intraperitoneal (IP) $(1 \mathrm{mg} / \mathrm{Kg})$ en ratas tratadas con APO o HAL. Igualmente, un grupo de ratas fue sometido a denervación dopaminérgica central mediante la $6 \mathrm{OH}$-dopamina (6OHDA). Los resultados mostraron que Ja116a induce una conducta

Autor de correspondencia: Jorge Angel. Laboratorio de Síntesis Orgánica, Diseño y Evaluación Farmacológiica de nuevos productos. Departamento de Química, Facultad Experimental de Ciencias, Universidad del Zulia, Maracaibo, Venezuela. Correo electrónico: jangel63@yahoo.com 
estereotipada de roídas y olfateos (sistema extrapiramidal) y acicalamientos y lamidas (sistema límbico), efectos que fueron bloqueados por el HAL y reducidos por la buspirona y la 6OHDA. Estos hallazgos indican que Ja116 actúa principalmente como un agonista dopaminérgico postsináptico, por lo que podría proponerse como un fármaco novedoso para el tratamiento de enfermedades neurodegenerativas tales como la Enfermedad de Parkinson.

\title{
Effect of the rigid 2-aminoindano, derived from acenaphthene, on stereotyped behavior in rats. Role of brain dopaminergic system.
}

Invest Clin 2020; 61 (3): 212-226

Key words: dopaminergiic aǵonist; prodrug; neurodegenerative diseases; Parkinson's disease.

\begin{abstract}
Neurodegenerative and neuropsychiatric diseases are directly related to alterations or dysfunction of the central dopaminergic system. Among the first are Parkinson's disease (PD), tardive dyskinesia, Tourette's syndrome, Huntington's chorea (HD), and among the second, Schizophrenia (EZ), addiction, mania, depression, and eating disorders. In order to contribute to the therapeutic arsenal that allows restoring the homeostasis of central dopaminergic neurotransmission, 1-amino-6,7,8,8a-tetrahydro acenaphthene 2 hydrochloride (Ja116a) was pharmacologically evaluated by quantification of its effects on stereotyped behavior in rats. Male Sprague-Dawley rats were used and were implanted with an intracerebroventricular cannula (ICV). Compound Ja116a was ICV administered $(5 \mu \mathrm{g} / 5 \mu \mathrm{L}$ and $50 \mu \mathrm{g} / 5 \mu \mathrm{L})$, in the presence or absence of apomorphine (APO); haloperidol (HAL); buspirone (BUS) or ziprasidone (ZIP); or intraperitoneally (IP) $(1 \mathrm{mg} / \mathrm{Kg})$ in rats treated with APO or HAL. Similarly, a group of rats was subjected to central dopaminergic denervation by $6 \mathrm{OH}-\mathrm{do}-$ pamine (6OHDA). The results show that Ja116a induces a stereotypical behavior of gnawing and sniffing (extrapyramidal system) and grooming and licking (limbic system), effects that were blocked by HAL and reduced by buspirone and 6OHDA. These findings indicate that Ja116 acts mainly as a postsynaptic dopaminergic agonist, so it could be proposed as a novel drug for the treatment of neurodegenerative diseases such as Parkinson's disease.
\end{abstract}

Recibido: 21-02-2020 Aceptado: 16-07-2020

\section{INTRODUCGIÓN}

La dopamina 1 (DA) (Fig. 1) en el Sistema Nervioso Central (SNC) está implicada en varias funciones vitales, tales como, la motricidad, la alimentación, el afecto, la recompensa, el sueño, la atención, la memoria, el aprendizaje y el humor (1). Su acción a nivel cerebral está mediada a través de cinco subtipos de receptores, $\mathrm{D}_{1}-\mathrm{D}_{5}$, los cuales, a su vez, se dividen en dos clases de receptores, los $\mathrm{D}_{1}$ y $\mathrm{D}_{2}(2)$; En los receptores $\mathrm{D}_{1}$ están

Vol. 61(3): 212 - 226, 2020 


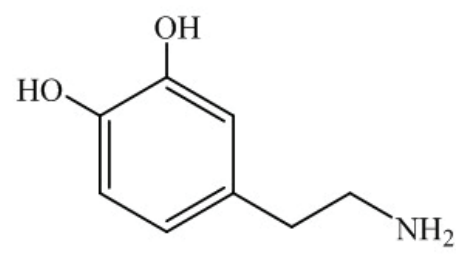

Rotamero $\alpha$

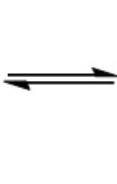

1

Fig. 1. Dopamina 1 y sus rotámeros.

presente los subtipos $\mathrm{D}_{1} \mathrm{y} \mathrm{D}_{5}$, mientras que, en la familia de $\operatorname{los} \mathrm{D}_{2}$, se incluyen los subtipos $\mathrm{D}_{2}, \mathrm{D}_{3}$ y $\mathrm{D}_{4}(3-6)$. La DA se encuentra principalmente en la sustancia negra, en el cuerpo estriado y en el sistema límbico. Las inervaciones dopaminérgicas son las más notables a nivel cerebral, en donde se han identificado cuatro vías principales en el cerebro de mamíferos como lo son las vías nigroestriatal, mesolímbica, mesocortical y tuberoinfundibular. Los sistemas mesolímbico y mesocortical participan en la modulación de la motivación, en el control emocional y en los procesos de cognición; el primero se involucra en los estímulos naturales y por drogas, mientras que el segundo (corteza prefrontal medial) se asocia con las funciones cognitivas como la memoria de trabajo, la atención y la conducta, entre otras (4-8). También es conocido que el sistema dopaminérgico a nivel cerebral, recibe inervaciones de fibras serotoninérǵicas (5-HT) que provienen del núcleo dorsal del rafe y del rafe medial. La acción fisiológica de la serotonina (5-HT) está mediada por siete clases de receptores. Los receptores 5-HT $1 \mathrm{a}, 5-\mathrm{HT}_{1 \mathrm{~b}}, 5-\mathrm{HT}_{3}$ y $5-\mathrm{HT}_{4}$ facilitan la liberación de DA. Adicionalmente, se sabe que los receptores $5-\mathrm{HT}_{2 \mathrm{a}}$ y $5-\mathrm{HT}_{2 \mathrm{c}}$ están ampliamente distribuidos en todo el cerebro, principalmente en áreas córtico límbicas, como la amígdala, el hipocampo, la corteza frontal, el área teǵmental ventral (VTA), el núcleo accumbens y el hipotálamo. En general, en el sistema mesocorticolimbico, la activación de los receptores $5-\mathrm{HT}_{2 \mathrm{a}}$ puede facilitar la liberación de dopamina
(DA) en condiciones de estimulación, pero no en condiciones basales; mientras que la activación del receptor $5-\mathrm{HT}_{2 \mathrm{c}}$ inhibe la actividad neuronal dopaminérǵica y la liberación de DA. Ambos subtipos de receptores ejercen un control facilitador sobre el eflujo de $\mathrm{DA}$, pero mientras que los receptores $5-\mathrm{HT}_{2 \mathrm{c}}$ actúan en condiciones basales, los receptores $5-\mathrm{HT}_{2 \mathrm{a}}$ intervienen solo cuando se activan las neuronas DA (9).

Los sistemas neuronales de 5-HT y DA cumplen una función importante en la regulación de la conducta tanto normal como anormal (6-8). La disfunción en las vías de neurotransmisión 5-HT y DA forma parte de la fisiopatología de diversos trastornos cerebrales (6) y por esta razón la DA ha sido implicada en trastornos neurodegenerativos y neuropsiquiátricos, tales como, la enfermedad de Parkinson (EP), la disquinesia tardía, el síndrome de Tourette, la Corea de Huntington (EH), la esquizofrenia (EZ), la adicción, la manía, la depresión, y los desórdenes de la alimentación, respectivamente $(1,7)$. El receptor $\mathrm{D}_{2}$ es uno de los más estudiados ya que es fundamental en el control de movimientos, la fisiopatología de la psicosis y la dependencia a drogas como la anfetamina y la cocaína (10). Este receptor es un blanco en la terapéutica para la enfermedad de Parkinson, la cual se caracteriza por la deficiencia de DA en las vías nigroestriadas del sistema extrapiramidal, con predominio de la secreción del neurotransmisor excitatorio en este sistema, la acetilcolina (11-14) y producción de un trastorno motor progresivo e 
invalidante cuyas manifestaciones clínicas en general, comprenden los desórdenes neuromotores característicos, la rigidez muscular, la lentitud de movimiento (bradicinesia) y/o la acinesia, el temblor en reposo, la inestabilidad postural y la dificultad para detener el movimiento. Además de ello, la EP está asociada a numerosos síntomas negativos tales como desórdenes cognitivos, depresión, ansiedad, falta de sueño, sensación de disturbio, disfunción autonómica y síntomas gastrointestinales (4-14). Los síntomas comienzan con rigidez muscular mínima e insidiosa o temblores casi imperceptibles, que evolucionan en forma lenta, pero inexorable, hacia diversas discapacidades funcionales que incluyen la incapacidad para caminar y comer, la facies inexpresiva, y las alteraciones en el habla y la escritura $(11,14,15)$. La EP, por su alta prevalencia, es una de las enfermedades más estudiadas desde el punto de vista químico medicinal, al ser considerada como un desorden universal, con una tasa bruta de incidencia de 4,5 a 19 por cada 100 mil habitantes por año. Algunos estudios afirman que es una enfermedad crónica de curso prolongado, por lo que su prevalencia es mucho mayor que la incidencia (16).

Las estrategias terapéuticas utilizadas para el tratamiento de la EP a largo de los años, consisten en restablecer el equilibrio de la neurotransmisión a través de fármacos que permitan esta acción. La acción terapéutica está orientada a aumentar la síntesis, la liberación y el tiempo de acción de la dopamina, así como también su acción directa sobre sus receptores. Así, el tratamiento clásico en los primeros estadios de la enfermedad consiste en reemplazar la dopamina con el uso de levo-dopa (precursor de la DA), para reponer los depósitos de la primera en el estriado. La L-DOPA, aunque comparte algunos de los efectos periféricos de la dopamina, estos son mucho menores. Debido a que la L-DOPA sufre descarboxilación fuera del sistema nervioso central y degradación rápida ulterior, se han empleado inhibidores de la dopa-descarboxilasa hepáti- ca, tales como la carbidopa, que permite que se alcancen concentraciones importantes en cerebro causando un mejor efecto terapéutico. Se ha empleado un tratamiento auxiliar cuando se trata la enfermedad de Parkinson con levodopa, que permite contrarrestar las reacciones extrapiramidales, uno de ellos es el trihexifenidilo, compuesto que inhibe de forma competitiva los receptores colinérgiicos centrales (del cuerpo estriado), de esta manera contribuye al equilibrio entre actividad colinérǵica y dopaminérǵica en los ganglios basales. Por otro lado, estos fármacos interactúan bloqueando los receptores colinérgicos a nivel del cuerpo estriado, a fin de obtener un antagonismo fisiológico. Otros tratamientos farmacológicos consisten en la administración de agonistas de los receptores de la dopamina, que estimulan directamente los receptores dopaminérgicos. Sin embargo, a pesar de que estos tratamientos inicialmente presentan mejoría clínica, su eficacia disminuye con el tiempo, debido al uso prolongado y en algunos casos, se pueda producir taquifilaxia $\mathrm{u}$ otros efectos colaterales en el paciente, lo que lleva a la suspensión de dichos fármacos (17).

Con la finalidad de obtener nuevos agentes capaces de restaurar la homeostasis de la neurotransmisión dopaminérgica en el SNC, se han diseñado y sintetizado en las últimas décadas numerosos compuestos que guardan las aproximaciones químico medicinales de la función dopaminérgica y que involucran las estrategias de los profármacos. El compuesto clorhidrato del 1-amino-6,7,8,8a-tetrahidroacenafteno 2 (Ja116a), mostró actividad dopaminérgica central como agonista y fue considerado como profármaco (18-22). Este aminoindano rígido no hidroxilado 2 además de haber mostrado la actividad dopaminérgica central también resultó ser un inhibidor de la enzima monoaminooxidasa (MAO) (22). Efectivamente, este compuesto al ser administrado intracerebroventricularmente (ICV) aumentó el volumen urinario y la excreción renal de sodio, efecto que fue bloqueado con el haloperidol $(18,20-22)$. Se ha sugeri- 
do que la acción del compuesto 2 (Ja116a) podría ser por la bioactivación metabólica, específicamente una hidroxilación aromática a través de la acción de una enzima monooxigenasa $(18,23,24)$, para generar el posible metabolito activo 3 (Fig. 2). Los trabajos pioneros realizados in vivo, mostraron efectos del compuesto 2 (Ja116a) sobre la conducta estereotipada, sin embargo la misma no ha sido cuantificada ni establecido su posible mecanismo de acción (19-24). Es por ello que, en vista de la evidencia que indica un posible efecto dopaminérgico central del compuesto 2 (Ja116a) y con el fin de aportar nuevos compuestos al arsenal terapéutico para el tratamiento de enfermedades degenerativas como la Enfermedad de Parkinson, se procedió a su evaluación farmacológica sobre la conducta estereotipada en ratas, ya que se ha establecido que la activación de los receptores dopaminérgicos a nivel del sistema límbico expresa la conducta estereotipada lamidas y acicalamiento, mientras que los olfateos y roídas son mediados por la activación de los receptores dopaminérgicos a nivel del sistema extrapiramidal (25).

\section{MATERIAL Y MÉTODOS}

\section{Protocolo experimental}

Se utilizaron ratas machos de la cepa Sprague-Dawley de 250 a 300 g, mantenidas bajo períodos alternativos de luz y oscuridad, con libre acceso al agua y alimento estándar (Ratarina ${ }^{\circledR}$, Protinal). Cinco días antes del ex- perimento, a cada rata se le implantó una cánula metálica en el ventrículo lateral-derecho, bajo anestesia con cilazina (Setton ${ }^{\circledR}$ al $2 \%$ ) $(1 \mathrm{mg} / \mathrm{Kg}$, i.p.) y relajación con ketamina, según las coordenadas: antero-posterior $-0,40$ $\mathrm{mm}$ del Bregma, 1,2 mm lateral y $3 \mathrm{~mm}$ ventral. Las cánulas empleadas como guía para la introducción de la aguja de inyección intracerebroventricular (ICV), se fabricaron utilizando agujas 20G con un largo inferior a $4 \mathrm{~mm}$, selladas con silicona y fijadas al cráneo permanentemente con cemento acrílico. La inyección ICV se realizó utilizando una inyectadora Hamilton de $10 \mu \mathrm{L}$ provista de un tope para aplicación precisa de los compuestos.

\section{Protocolo para la evaluación de la conducta estereotipada}

La conducta estereotipada, es decir, una actividad motora repetitiva y sin propósito, se evaluó mediante observación, para lo cual se colocó cada animal dentro de una caja de acrílico transparente con las siguientes dimensiones: $32 \times 28 \times 28 \mathrm{~cm}$., con un periodo previo de 15 minutos de habituación. Las observaciones se realizaron durante 60 minutos, divididos en 10 intervalos de 6 minutos cada uno. Para cada una de las pruebas, se utilizaron grupos de 4 animales y las conductas evaluadas fueron: lamidas, roídas, olfateos y acicalamientos. Los datos recolectados se registraron empleando en una computadora dotada de un software para contar el número de movimientos estereotipados.

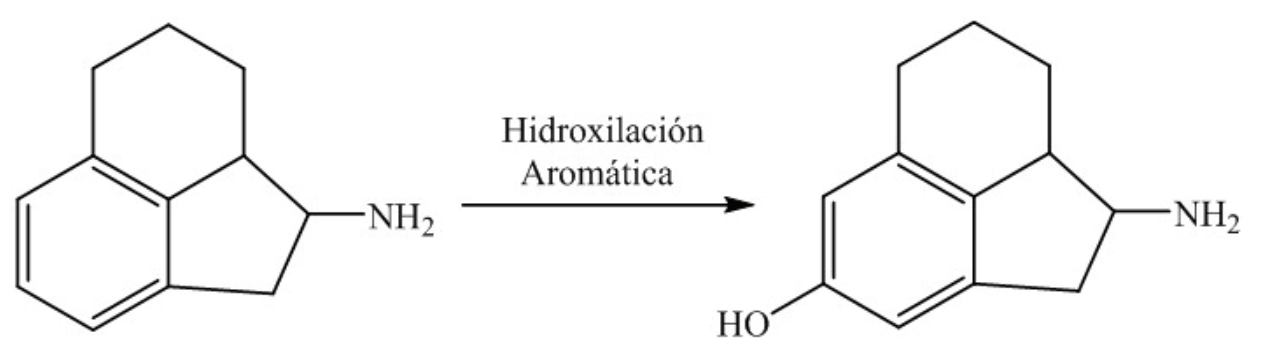

2 (Ja116a)

Fig. 2. Bioactivación Metabólica del compuesto 2 (Ja116a). 


\section{Protocolo de administración} de los compuestos evaluados

El compuesto 2 (Ja116a) fue disuelto en solución salina fisiológica. Se emplearon dos vías de administración: 1 . ICV, en un volumen de inyección de $5 \mu \mathrm{L}$, a dosis de $5 \mu \mathrm{g} / 5 \mu \mathrm{L}$ y $50 \mu \mathrm{g} / 5 \mu \mathrm{L}$. Como control se empleó solución salina $(5 \mu \mathrm{L}) ;$ y 2 . Vía Intraperitoneal (IP) a una dosis de $1 \mathrm{mg} / \mathrm{Kg}$ de peso del animal. Se emplearon 4 animales por cada grupo experimental.

Todos los pretratamientos fueron realizados por vía intraperitoneal, 15 minutos antes de la administración ICV del compuesto 2 (Ja116a) o de solución salina, y fueron los siguientes: 1. Haloperidol (1mg/Kg) (Haldol $50 \mathrm{mg} / \mathrm{mL}$, solución inyectable, Janssen Pharmaceutica), antagonista de los receptores dopaminérǵicos; 2. Ziprasidona (1mg/ Kg) (Geodon ${ }^{\mathrm{R}}$, Laboratorios Pfizer), antipsicótico atípico; 3. Buspirona (1mg/Kg) (Clorhidrato de buspirona, Buspar, comprimidos de 20 mg, Dalpas ${ }^{\circledR}$, Biotech Laboratorios), un agonista parcial de los receptores de serotonina $\left(5 \mathrm{HT}_{1 \mathrm{a}}\right) ; 4$. Apomorfina $(1 \mathrm{mg} / \mathrm{Kg})$ (APO-go PEN $10 \mathrm{mg} / \mathrm{mL}$, solución inyectable), agonista dopaminérǵico $\mathrm{D}_{1}-\mathrm{D}_{2}$ (18-21). Cabe señalar, que los compuestos se inyectaron por la vía ICV, ya que ello permite: 1) atravesar la barrera hemato-encefálica, la cual impide la entrada de ciertos tipos de compuestos, especialmente polares, al cerebro; 2) reducir las dosis y consecuentemente disminuir la cantidad de compuestos que necesitan ser sintetizados para las pruebas biológicas.

\section{Protocolo de la denervación dopaminérgica central}

A un grupo de ratas canuladas ICV se le realizó una lesión con 6-hidroxidopamina (6-OHDA) (Sigma Aldrich, Saint Louis, MO) $(112 \mathrm{mM}, \mathrm{pH}=7,4)$. Para ello se inyectó la solución neurotóxica en el ventrículo lateralderecho a una dosis de $200 \mu \mathrm{g} / 5 \mu \mathrm{L}, 48$ y $72 \mathrm{~h}$ previas a la administración-ICV del compuesto 2 (Ja116a) $(50 \mu \mathrm{g} / 5 \mu \mathrm{L}, \mathrm{n}=4)$. Como control se usó solución salina $(5 \mu \mathrm{L}, \mathrm{n}=4)$.

\section{Análisis estadístico}

Los resultados fueron expresados como la media \pm E.E.M. La signnificancia de los resultados fue analizada mediante el análisis de varianza de una y dos vías (ANOVA) (26) y la prueba de Newman-Keuls. Un valor de $p<0,05$ fue considerado significativo. El análisis de los resultados y la elaboración de los gráficos se realizaron empleando el programa GraphPad Prism versión 5.1.

\section{RESULTADOS}

\section{Efecto del compuesto 2 (Ja116a)} administrado por vía ICV sobre la conducta estereotipada en ratas. Efecto del pretratamiento con haloperidol, buspirona, ziprazidona y apomorfina

Tal y como se observa en la Fig. 3, el compuesto 2 (Ja116a) administrado por vía ICV $(5 \mu \mathrm{g} / 5 \mu \mathrm{L})$ incrementó de forma significativa las conductas estereotipadas de lamidas, acicalamientos y en menor grado, aunque significativo, las de roída y olfateo. Sin embargoo, la administración de la dosis $50 \mu \mathrm{g} / 5 \mu \mathrm{L}$ solo aumentó las lamidas y los acicalamientos. El pretratamiento con el antipsicótico típico haloperidol bloqueó completamente, mientras que la buspirona, un agonista parcial $5 \mathrm{HT}_{1 \mathrm{a}}$ y antagonista $\mathrm{D}_{2}$ redujo, las respuestas estereotipadas inducidas por el compuesto 2 (Ja116a), a ambas dosis. Por su parte, el pretratamiento con el antipsicótico típico ziprasidona, produjo más bien un incremento adicional y significativo al producido por el compuesto 2 (Ja116a) en las lamidas y los acicalamientos. La denervación química con 6OHDA redujo significativamente las lamidas y olfateos inducidos por la inyección ICV de compuesto 2 (Ja116a) a la dosis de $50 \mu \mathrm{g} / 5 \mu \mathrm{L}$.

\section{Efecto de la administración} intraperitoneal del compuesto 2 (Ja116a) sobre la conducta estereotipada en ratas

En la Fig. 4 se muestra que la administración intraperitoneal del compuesto 2 (Ja116a) (1mg/Kg) incrementa de forma 

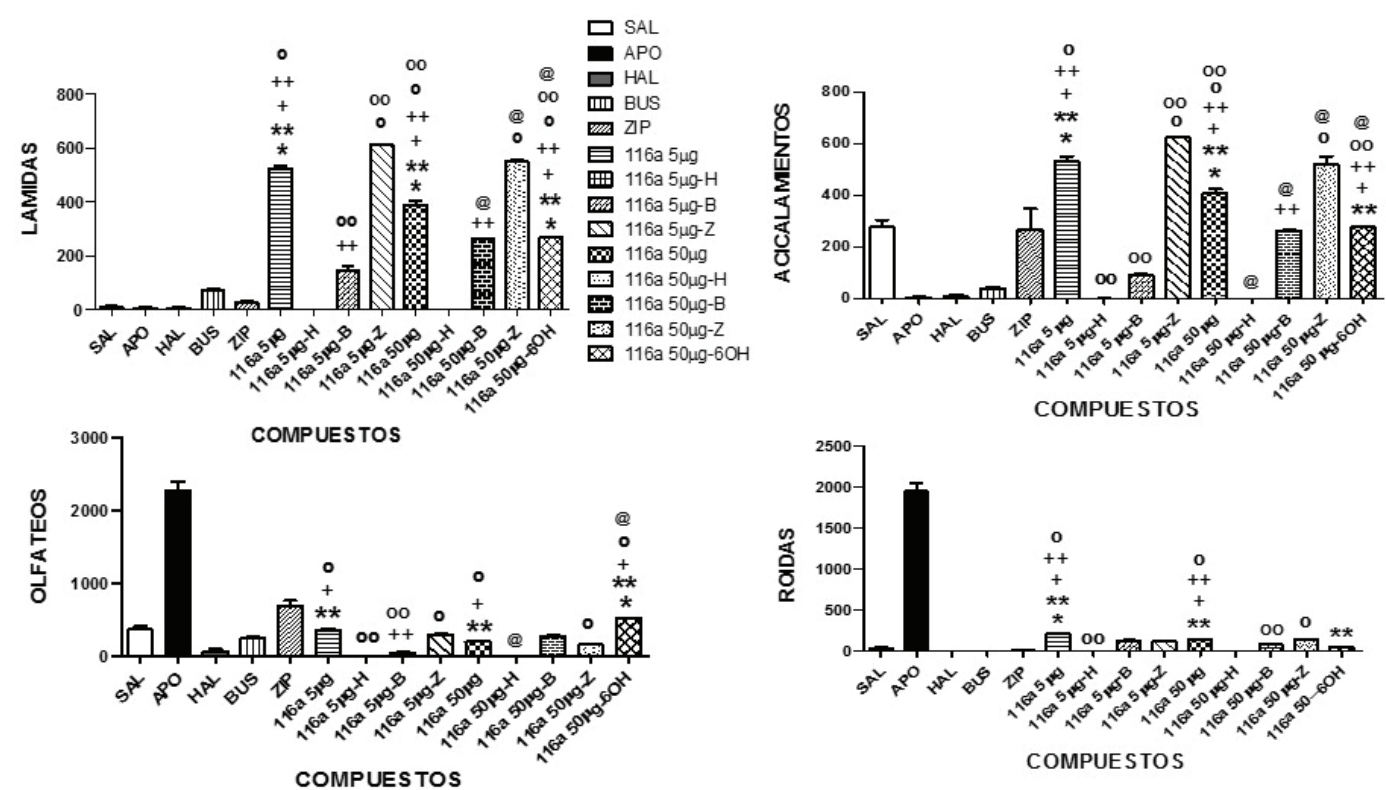

Fig. 3. Efecto del compuesto 2 (Ja116a) $(5 \mu \mathrm{g} / 5 \mu \mathrm{L}$ y $50 \mu \mathrm{g} / 5 \mu \mathrm{L})$ sobre la conducta estereotipada en ratas. En las ordenadas, la suma de las conductas medidas. En las abseisas, los compuestos evaluados. Las observaciones se realizaron durante una hora. Los resultados se expresaron como $\mathrm{X} \pm$ E.E.M. de cuatro mediciones independientes. Los datos fueron analizados mediante análisis de variancia (ANOVA) de una y dos vías, y la prueba de Newman-Keuls; $\mathrm{n}=4$ animales por ǵrupo. "diferencia significativa (ds) vs. salina (SAL); "*ds vs. apomorfina (APO); +ds vs. haloperidol (HAL); ++ ds vs. buspirona (BUS);

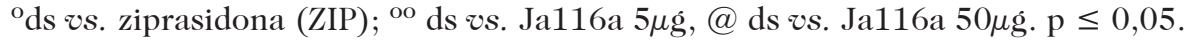
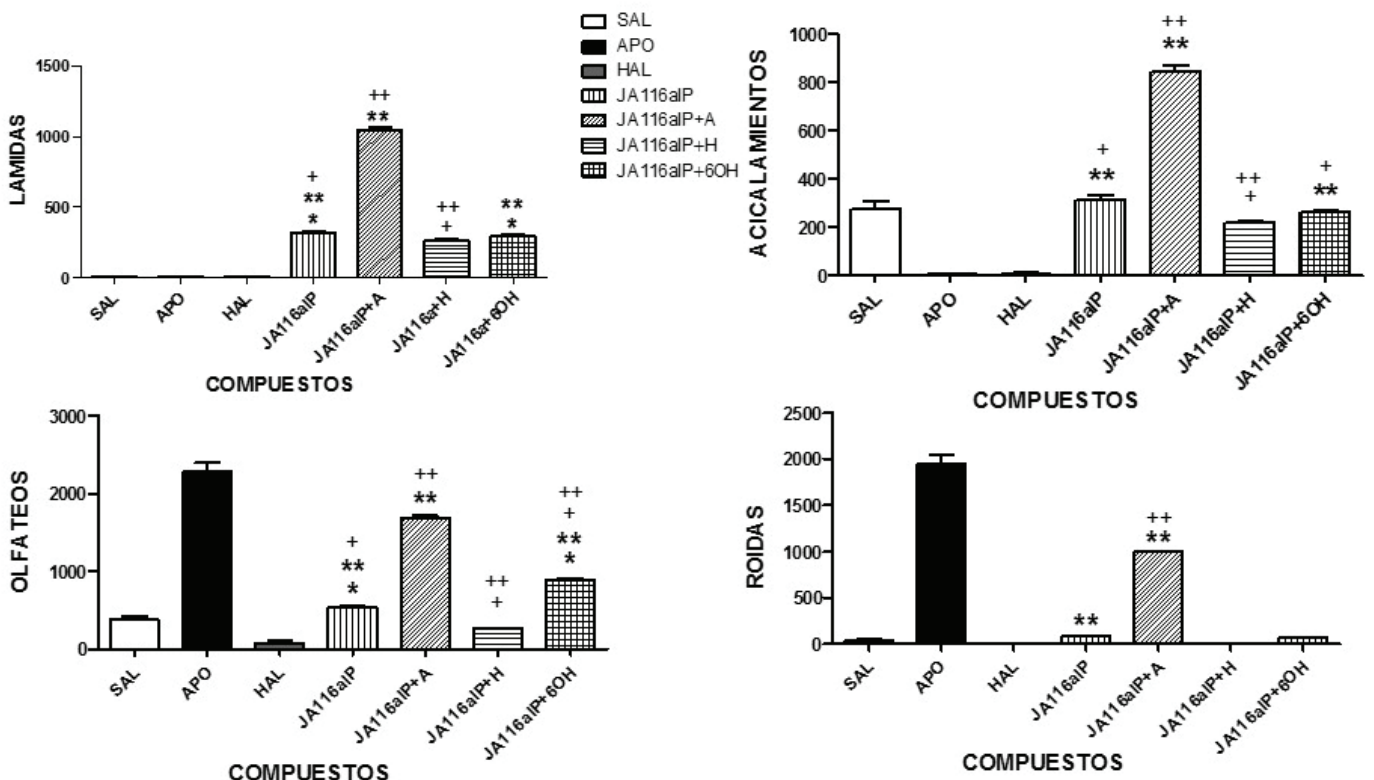

Fig. 4. Efecto del compuesto 2 (Ja116a) administrado IP sobre la conducta estereotipada en ratas. En las ordenadas, la suma de las conductas medidas. En las abscisas, los compuestos evaluados. Las observaciones se realizaron durante una hora. Los resultados se expresaron como $\mathrm{X} \pm$ E.E.M. de cuatro mediciones independientes. Los datos fueron analizados mediante análisis de variancia (ANOVA) de una y dos vías, y la prueba de Newman-Keuls; $\mathrm{n}=4$ animales por grupo. "diferencia significativa (ds) vs. salina (SAL); **ds vs. apomorfina (APO); +ds vs. haloperidol (HAL) ++ ds vs. Ja116a IP $2 . p \leq 0,05$. 
significativa las conductas estereotipadas de lamidas, olfateos y acicalamientos. El pretratamiento con haloperidol o la denervación dopaminérgica con 6OHDA redujeron significativamente el efecto compuesto 2 (Ja116a) sobre la conducta estereotipada. Por su parte la administración de apomorfina per se produjo una respuesta significativa de roída y olfateo, y el pre-tratamiento con apomorfina más bien potenció de forma significativa la respuesta de las 4 conductas estereotipadas inducidas por compuesto 2 (Ja116a).

\section{DISCUSIÓN}

La posible participación del sistema dopaminérgico cerebral en la acción del compuesto 2 (Ja116a) administrado ICV, está avalada por los hallazgos de Orfila y col. (20), quienes demostraron que el haloperidol y la denervación dopaminérgica central fueron capaces de bloquear la acción natriurética y diurética, tanto de Ja116a como de la dopamina ICV. Igualmente, Charris y col. (22) demostraron que este compuesto produjo una inhibición, dependiente de la dosis, de la actividad de la enzima MAO cortical y hepática, lo que sugiere que el compuesto 2 (Ja116a) para poder ejercer su acción central requiere de bioactivación metabólica, mediante una hidroxilación aromática mediada por la enzima monooxigenasa y así generar el posible metabolito activo $\mathbf{3}(18,23,24)$.

La estereotipia se define como un comportamiento excesivo y repetitivo, que es el principal componente de varios desórdenes psiquiátricos, incluidos el autismo infantil (25) y la esquizofrenia (27). Se ha establecido que la estereotipia (olfateos y roídas), es un comportamiento dependiente de la dopamina que se debe a las proyecciones dopaminérgiicas de la región de los núcleos caudado y putamen y constituye el sustrato neural del comportamiento estereotipado inducido por la apomorfina, un agonista mixto de los receptores de dopamina $\mathrm{D}_{1}-\mathrm{D}_{2}$, en animales (28). La activación de los receptores de do- pamina $\mathrm{D}_{1}-\mathrm{D}_{2}$ localizados en el núcleo estriado se expresa como un aumento de las roídas y los olfateos, cuyas respuestas son propias del sistema extrapiramidal, en cambio la activación de estos receptores en el sistema límbico expresa la conducta estereotipada de lamidas y acicalamientos (18,27-29).

Ahora bien, en aras de interpretar los resultados y lograr establecer una aproximación más acertada sobre el mecanismo de acción del compuesto en estudio, es preciso resaltar el sitio de acción de las drogas utilizadas como patrones. El agonista dopaminérgico apomorfina y el antagonista haloperidol (antipsicótico típico) interactúan a través los receptores $\mathrm{D}_{1}-\mathrm{D}_{2}$. La ziprasidona es un antagonista dopaminérgico y se diferencia del haloperidol por ser un antipsicótico atípico que bloquea los receptores $5 \mathrm{HT}_{2 \mathrm{a}} \mathrm{y}$ $\mathrm{D}_{2}$, en una proporción de $8: 1$ respectivamente, además es un agonista del receptor $5 \mathrm{HT}_{1 \mathrm{a}}$ $(20,29)$. La buspirona (azaspirodecanediona) es un ansiolítico no benzodiazepínico sin relación estructural con otros psicotrópicos. Se sabe que es un aǵonista parcial postsináptico de los receptores $5-\mathrm{HT}_{1 \mathrm{a}} \mathrm{y}$ antagonista del receptor $\mathrm{D}_{2}(30)$.

En el presente estudio se demostró que la administración central (ICV) o periférica (IP) del compuesto 2 (Ja116a) induce un comportamiento estereotipado a nivel del sistema extrapiramidal (roídas y olfateos) y en el sistema límbico (acicalamientos y lamidas). El hecho que el haloperidol (antagonista no selectivo) bloquea las conductas estereotipadas inducidas por compuesto 2 (Ja116a) demuestra su acción dopaminérgica en ambos sitios. Por otra parte, el pretratamiento con la ziprasidona, incrementó las respuestas conductuales lamidas y acicalamientos, propios del sistema límbico. Estos resultados están en concordancia con lo reportado por Angel y col. (31-35) quienes demostraron que la adición de ziprasidona, aumentó las lamidas y los acicalamientos. Al respecto, se ha demostrado que el bloqueo con los antipsicóticos atípicos ziprasidona y clozapina, de las conductas estereotipadas 
ejercidas por la apomorfina, induce un aumento en las lamidas y los acicalamientos. Esto es debido al aumento del tono dopaminérgico, ya que al activar los receptores $5 \mathrm{HT}_{1 \mathrm{a}}$ y bloquear los $5 \mathrm{HT}_{2 \mathrm{a}}$, genera un incremento selectivo de la liberación de dopamina en una región de la corteza prefrontal (sistema mesocortical). Por otro lado, se conoce que tanto la clozapina como la ziprasidona reducen la transmisión dopaminérgica al bloquear los receptores $\mathrm{D}_{2}$ (sistema mesolímbico). Estos mecanismos moderan la reducción de la función dopaminérgica, lo cual explica la eficacia de la clozapina y la ziprasidona, sobre los síntomas positivos con menos producción de los movimientos extrapiramidales involuntarios, al mismo tiempo que se produce un bloqueo serotoninérgico, lo cual podría explicar su eficacia sobre los síntomas negativos y los desórdenes del humor $(31,36)$. Existe evidencia contradictoria que indica que los receptores $5-\mathrm{HT}_{2 \mathrm{a}}$ y $5-\mathrm{HT}_{2 \mathrm{c}}$ están ampliamente distribuidos en todo el cerebro, principalmente en áreas córtico límbicas, como la amígdala, el hipocampo, la corteza frontal, el área teǵmental ventral (VTA), el núcleo accumbens y el hipotálamo. En general, en el sistema meso córtico límbico, la activación de los receptores 5-HT $2 \mathrm{a}$ puede facilitar la liberación de dopamina (DA) en condiciones de estimulación, pero no en condiciones basales; mientras que la activación del receptor 5-HT $\mathrm{H}_{2 \mathrm{c}}$ inhibe la actividad neuronal dopaminérgica y la liberación de DA (37). Ambos subtipos de receptores ejercen un control facilitador sobre el eflujo de $\mathrm{DA}$, pero mientras que los receptores $5-\mathrm{HT}_{2 \mathrm{c}}$ actúan en condiciones basales, los receptores 5 - $\mathrm{HT}_{2 \mathrm{a}}$ intervienen solo cuando se activan las neuronas de DA. Por lo tanto, nuestros resultados de aumento en los acicalamientos y las lamidas inducidos por el compuesto 2 (Ja116a) en presencia de ziprasidona, podrían alternativamente interpretarse como debidos a su interacción como agonista de los receptores $5 \mathrm{HT}_{1 \mathrm{a}}$ y $5 \mathrm{HT}_{2 \mathrm{c}}$, lo cual estaría aumentando la activación dopaminérgica a nivel del sistema límbico en concomitancia con la acción per se del compuesto en estudio. Se descartaría la participación del receptor 5- $\mathrm{HT}_{2 \mathrm{a}}$ ya que su intervención ocurre en un sistema dopaminérgico estriatal estimulado, y no fue el caso (9).

Ahora bien, al considerar la aproximación químico medicinal en el diseño del compuesto 2 (Ja116a) y relacionarla con los posibles sitios de acción, se estableció que contiene dos tipos de farmacóforos, los fragmentos fenilisopropilamino y feniletilamino (Fig. 5). El fenilisopropilamino es el responsable de la actividad como inhibidor de la enzima MAO-B (IMAO-B) y su función es aumentar la vida media de la DA endógena (22). El segundo es el fragmento feniletilamino, que junto con el fenilisopropilamino son los responsables que el compuesto 2 (Ja116a) se comporte como un compuesto anfetamino-similar, y actúe a nivel presináptico aumentando la liberación de la $\mathrm{DA}$ $(18,20,21)$. Si el fragmento feniletilamino, fuese bioactivado por una monooxigenasa generaría el farmacóforo dopaminérgico, el m-hidroxifeniletilamino (Figss. 2 y 5), cuya acción sería la estimulación de los receptores $\mathrm{D}_{2}$ postsinápticos. Hasta ahora los resultados parecen indicar que la acción del compuesto 2 (Ja116a) ocurre través de mecanismos dopaminérgicos, los cuales podrían ser la resultante de una acción presináptica y/o postsináptica. En la vía presináptica el compuesto 2 (Ja116a) podría estar aumentado la liberación, alterando el almacenamiento, metabolismo y/o síntesis de la DA endógena; ésta acción podría ocurrir posiblemente ya sea inhibiendo la enzima MAO, o bien permitiendo la liberación de la DA desde los sitios de almacenamiento en la neurona presináptica; mientras que en la vía postsináptica estaría interactuando sobre su propio receptor dopaminérgíco. Para dilucidar este aspecto, se empleó la denervación dopaminérgica selectiva con 6OHDA, la cual es considerada como un método rutinario para la destrucción de los terminales nerviosos catecolaminérgicos en el sistema nervioso central y ha sido ampliamente empleado para inducir la Enfer- 

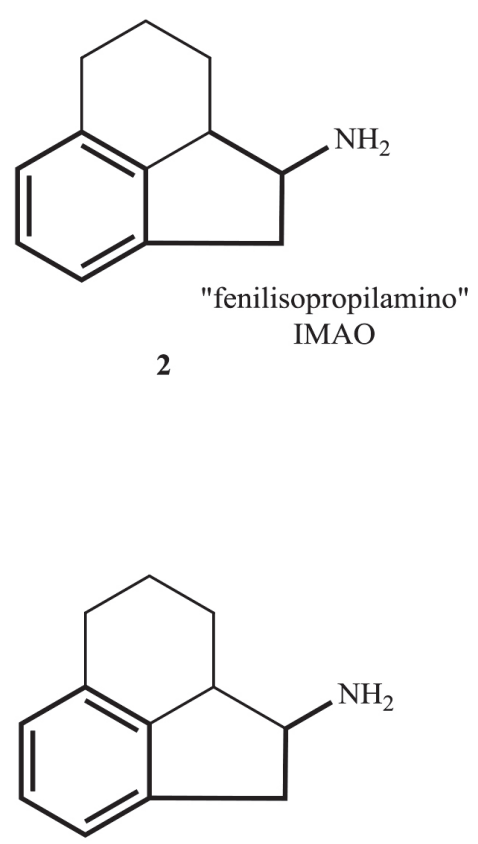

"feniletilamino" acción indirecta (presináptica)

Fig. 5. Farmacóforos insertos en los compuestos 2 y 3.

medad de Parkinson experimental (38-40). Los resultados presentes demuestran que la denervación dopaminérgiica no alteran significativamente la respuesta estereotipada inducida por el compuesto 2 (Ja116a), ya que solo se redujeron parcialmente las lamidas y los acicalamientos, y aumentó levemente el olfateo inducido por la vía ICV/IP. Estos hallazgos parecen indicar que la actividad del compuesto 2 (Ja116a) ocurre principalmente sobre el receptor postsináptico y que para que ocurra esta respuesta dopaminérgica central, la bioactivación metabólica a nivel presináptico del compuesto en estudio (Ja116a) no es indispensable $(18,20,21)$. Al no existir la formación del farmacóforo la droga no es un agonista dopaminérgico y los resultados obtenidos después de la denervación, apoyan esta sugerencia. Sin embargo, no descartamos la posibilidad que este compuesto sea activado metabólicamente a otros niveles. Efectivamente, a pesar que en nuestro protocolo experimental no fue po-

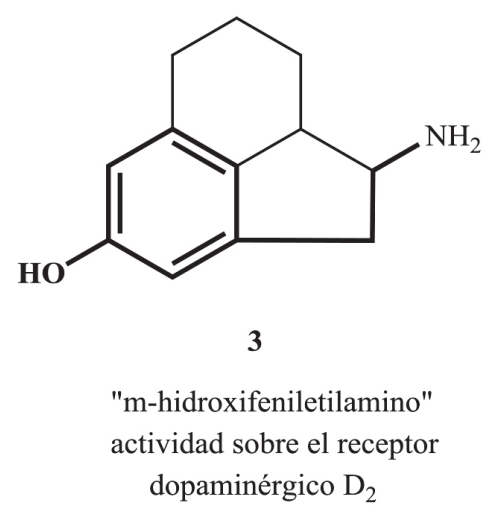

sible cuantificar el contenido de dopamina en las áreas de interés como son el núcleo acumbens y el estriado, otros autores han demostrado que la inyección intracerebral de 6OHDA produce una destrucción selectiva de neuronas dopaminérǵicas nigrales, de los terminales estriatales y una depleción en los niveles de dopamina, serotonina, encefalina y sustancia $\mathrm{P}$ estriatales, y la máxima reducción de las concentraciones de dopamina se produce entre el tercer y el cuarto día tras la inyección. La degeneración neuronal afecta por igual tanto a las neuronas dopaminérgicas de la Sustancia Nigra pars compacta que proyectan al estriado como a las del área tegmental ventral que forman parte del sistema mesolímbico (41). Por ello, al no determinarse la concentración de DA en las áreas cerebrales de interés, queda la posibilidad que la denervación no haya sido totalmente efectiva y por lo tanto, el compuesto 2 (Ja116a) podría haber actuado parcialmente a nivel presináptico. 
Parte de la respuesta agonística dopaminérgica podría estar mediada por la acción del compuesto 2 (Ja116a) sobre las neuronas serotoninérgicas. Para evaluar esta posibilidad se empleó el pretratamiento con la buspirona, un agonista parcial del receptor $5 \mathrm{HT}_{1 \mathrm{a}}$ postsináptico, esperando que la respuesta farmacológica resultante entre un agonista parcial y uno total, fuese un antagonismo a alta dosis y un agonismo a baja dosis (30,42). Si el compuesto 2 (Ja116a) seguía este comportamiento, indicaba que la actividad del compuesto 2 (Ja116a) resultaba de su interacción como agonista del receptor $5 \mathrm{HT}_{1 \mathrm{~A}}$. Los agonistas del receptor $5 \mathrm{HT}_{1 \mathrm{a}}$, aumentan la liberación de dopamina a nivel central. Nuestros resultados revelan que la respuesta conductual estereotipada del compuesto 2 (Ja116a) con la buspirona, no se comporta de acuerdo al patrón mostrado entre un agonista parcial y un agonista total y la respuesta farmacológica obtenida indica que no está interactuando sobre el receptor $5 \mathrm{HT}_{1 \mathrm{a}}$. Por ello, las respuestas estereotipadas parecen ser netamente dopaminérgicas, ya que, ambas dosis, mostraron un bloqueo en las cuatro conductas estereotipadas. La buspirona además de ser agonista parcial sobre el receptor $5 \mathrm{HT}_{1 \mathrm{a}}$, es un antaǵonista $\mathrm{D}_{2}(30)$. Esta última acción de la buspirona, explicaría la respuesta antagónica observada en el presente estudio frente a la acción agonística del compuesto 2 (Ja116a).

Es posible argumentar en base al sustrato neuroanatómico, la diferencia de la acción del compuesto 2 (Ja116a) en ratas tratadas con 6OHDA, en la que la denervación bloqueó la acción diurética y natriurética (20), pero no así la respuesta estereotipada (presentes resultados). Efectivamente, se sabe que el sistema ventricular cerebral está conformado por una serie de cavidades (ventrículos) interconectadas entres sí, dos ventrículos laterales que tienen forma de "C", derecho e izquierdo, y están rodeados por estructuras del sistema límbico (tálamo, cuerpo calloso) y de los ganglios basales (caudado), entre otros. Estos a su vez se comunican con el tercer ventrículo a través del agujero interventricular o agujero de Monro, que se encuentran entre el tálamo (estructura límbica) y la parte anterior del fórnix (conjunto de fibras nerviosas que forma parte del sistema límbico), mientras que el tercer ventrículo se aloja entre el tálamo derecho e izquierdo, formando una estrecha ranura en el diencéfalo. El tercer ventrículo se comunica con el cuarto a través del acueducto de Silvio. Dado que la mayor parte del sistema ventricular está relacionado con el sistema límbico, y sólo en los ventrículos laterales hay estructuras basales, es posible que la totalidad de las conductas observadas sean límbicas (lamidas y acicalamientos), mientras que las conductas basales (roídas y olfateos) fueron separadas. Sólo se observó la totalidad de estas conductas cuando el compuesto 2 (Ja116a) (IP) se administró a un grupo de ratas pretratadas con apomorfina, donde las cuatro conductas evaluadas aumentaron significativamente, hay que resaltar que la apomorfina tiene conductas basales y no límbicas. El segundo aspecto se basa en el hecho que los ventrículos laterales son los más grandes y por ende hay mayor área de contacto, para el intercambio de sustratos y metabolitos desde el líquido cefalorraquídeo hacia el cerebro y viceversa. En este punto ya podemos hacer una aproximación acerca del mecanismo de acción, al explorar el tránsito del compuesto 2 (Ja116a) por el sistema ventricular y el comportamiento farmacológico que ejerce sobre el sistema límbico y los ganglios basales, en ratas normales y desnervadas. Efectivamente, el compuesto 2 (Ja116a) fue administrado en el ventrículo lateral-derecho, en dicha cavidad gran cantidad es transportada o difundida hacia el cerebro, donde entra en contacto con las estructuras límbicas y basales que limitan con el ventrículo; allí podrían estar ocurriendo los siguientes eventos: a. El compuesto 2 estaría aumentando la vida media de la DA endógena al inhibir la enzima MAO (21); b. Aumentaría la liberación de DA endógena por su acción indirecta 
sobre la neurona presináptica $(18,20,21)$; c. Se activaría metabólicamente al incorporar el oxidrilo en el anillo bencénico en posición meta, para de esa forma poseer el farmacóforo del receptor $\mathrm{D}_{2}$ (Fiǵ. 2). Es por ello que en ratas normales o lesionadas se observaron las respuestas agonísticas dopaminérgicas, tal es el caso que en las ratas normales, se apreciaron dos conductas límbicas (lamidas y acicalamientos) a la dosis de $50 \mu \mathrm{g} / 5 \mu \mathrm{l}$, mientras que a la dosis de $5 \mu \mathrm{g} / 5 \mu \mathrm{L}$, se observaron tres conductas, las dos límbicas (lamidas y acicalamientos) y una basal (roídas). En cambio, cuando las ratas fueron desnervadas la acción del compuesto 2 (Ja116a) fue postsináptica a la dosis de $50 \mu \mathrm{g} / 5 \mu \mathrm{L}$, y sólo aparecieron dos conductas estereotipadas, una límbica (lamidas) y una basal (olfateos). En la ruta hacia el cuarto ventrículo hay estructuras límbicas que pueden ser estimuladas por la absorción de una parte del remanente del compuesto en estudio y el restante cuando llega al cuarto ventrículo es absorbido e interactúa sobre los recesos del tipo hipotalámico e infundibular. En este nivel está también sucediendo la inhibición de la enzima MAO, la liberación de DA endógena por su acción indirecta sobre la neurona presináptica y la bioactivación metabólica para generar la forma activa del profármaco (Ja116a) e interactuar a nivel postsináptico. Una vez absorbido el compuesto 2 (Ja116a) per se, y una vez bioactivado, interactúa postsinápticamente con su receptor, a la vez que al inhibir la enzima MAO aumentaría la liberación de DA endógena. Se ha propuesto que la falta de DA endógena en los terminales presinápticos en ratas lesionadas presinápticamente con la 6OHDA, resulta en una "regulación hacia arriba" de los receptores dopaminérgicos postsinápticos, es decir una supersensibilidad de receptores dopaminérgicos postsinápticos, donde la cantidad de ligando ya activado y la DA endógena liberada es mínima, para la máxima ocupación de los receptores postsinápticos necesarios capaces de desencadenar la actividad dopaminérgica como agonista.
Es bien conocido que las respuestas conductuales estereotipadas son el producto de la activación de los receptores dopaminérgícos del tipo $\mathrm{D}_{1} \mathrm{y}_{2}$ a nivel central, siendo que el receptor $\mathrm{D}_{1}$ estimula la conducta estereotipada ró́da mientras que las lamidas, los olfateos y los acicalamientos son promovidas por la estimulación del receptor $\mathrm{D}_{2}(43,44)$. La evidencia farmacológica indica que posiblemente la activación dopaminérgica ejercida por el compuesto 2 (Ja116a) este mediada por la interacción con los receptores dopaminérǵicos $\left(\mathrm{D}_{2}>\mathrm{D}_{1}\right)$. Así, al realizar el análisis de las respuestas estereotipadas control se puede inferir que las mismas resultan de la activación de ambos tipos de receptores $\left(\mathrm{D}_{1}-\mathrm{D}_{2}\right)$, siendo la respuesta más selectiva hacia el receptor $\mathrm{D}_{2}$ a la dosis de $50 \mu \mathrm{g} / 5 \mu \mathrm{L}$, que lo mostrado a la dosis de $5 \mu \mathrm{g} / 5 \mu \mathrm{L}$, ya que en la primera sólo hubo el aumento de las lamidas y los acicalamientos; mientras que la segunda mostró las conductas típicas de la activación del receptor $\mathrm{D}_{2}, \mathrm{y}$ adicionalmente se activó el receptor $\mathrm{D}_{1}$ con la conducta roídas. Mientras que en las ratas desnervadas las respuestas conductuales estereotipadas inducidas por las vías ICV e IP, fueron del tipo $\mathrm{D}_{2}$ ya que en la primera aumentaron dos conductas (lamidas y olfateos), mientras que por la vía IP aumentaron tres conductas (lamidas, olfateos y acicalamientos). Sin embargo, el pretratamiento con apomorfina permite observar la activación de ambos tipos de receptores, al aumentar las cuatro conductas estereotipadas. La apomorfina es un fármaco con actividad mixta $\left(\mathrm{D}_{1}-\mathrm{D}_{2}\right)$ como agonista, y este efecto con en conjunto con el compuesto en estudio produjo la totalidad de las conductas por activación de las estructuras límbicas y la potenciación de las conductas basales.

El compuesto 2 (Ja116a), es un profármaco que presenta en su estructura los fragmentos farmacofóricos, el fenilisopropilamino (responsable de la actividad IMAO) y el feniletilamino (acción indirecta) y al ser metabolizado se incorpora dentro de su estructura el fragmento m-hidroxifeniletilamina. 
Este farmacóforo (Fig. 2) es el responsable de la acción postsináptica $\mathrm{D}_{2}$ como agonista. Es bien conocido que los receptores $\mathrm{D}_{1}$ requieren de la presencia de dos grupos $-\mathrm{OH}$ (en posición meta y para) y los $\mathrm{D}_{2}$ son menos específicos y requieren únicamente del $-\mathrm{OH}$ en posición meta (45). Basándose en estos arǵumentos, la conducta roída es el producto de la activación del receptor $\mathrm{D}_{1}(43,44)$ por la acción de la dopamina endógena, ya que la forma no metabolizada del compuesto 2 concomitantemente actúa liberándola desde los terminales presinápticos y prolongando su vida media al inhibir la MAO (18,20-22); en cambio la forma metabolizada activa los receptores $\mathrm{D}_{2}$ por tener el farmacóforo (mhidroxifeniletilamino) y expresa las conductas estereotipadas lamidas, olfateos y acicalamientos $(43,44)$.

Es importante mencionar lo acertado de la aproximación químico medicinal en el diseño de este compuesto, ya que está en concordancia con los resultados farmacológicos que revelan la acción agonística a través de la activación de los mecanismos dopaminérgicos sobre el sistema nervioso central. Es decir, que la actividad farmacológica como agonista ejercida por el compuesto 2 (Ja116a), está potenciada por los mecanismos antes mencionados y aquí se valida lo acertado de la aproximación químico medicinal en el diseño del fármaco, al considerar todas las estrategias farmacofóricas enmarcadas dentro del concepto de los profármacos; sólo que en este caso, bajo esta forma (no metabolizada) es activo en forma indirecta (IMAO y aumentando la DA endógena) y cuando es metabolizado es un agonista postsináptico con mayor afinidad hacia los receptores $\mathrm{D}_{2}$, los resultados farmacológicos publicados (20-22) y los presentes, están en plena concordancia con lo antes mencionado.

Finalmente, el compuesto 2 (Ja116a), podría constituir un fármaco potencial a ser incluido dentro del ǵrupo de medicamentos empleados en la terapéutica de las enfermedades neurodegenerativa, específicamente en la enfermedad de Parkinson.

\section{AGRADECIMIENTO}

El autor (JA) dedica este manuscrito a la memoria del Profesor Dr. José Gregorio Hernández Cisnero (1864-1919)† Fundador de la Medicina Experimental en Venezuela. Este trabajo fue subvencionado por los proyectos FDI No 02-2017, Programa CONDESCG-0239-17 y CONDES-CG-0378-15.

\section{REFERENCIAS}

1. Sachar B, Zuk R, Gazawi H, Ljubuncic P. Dopamine toxicity involves mitochondrial complex I inhibition: implications to dopamine-related neuropsychiatric disorders. Biochem Pharm 2004; 67 (10): 1965-1974.

2. Zhang A, Neumeyer J, Baldessarini R. Recent progress in development of dopamine receptor subtype-selective agents: potential therapeutics for neurological and psychiatric disorders. Chem Rev 2007; 1(28): 274-302.

3. Long J, Heintz S, Cannon J, Kim J. Inhibition of the sympathetic nervous system by 5,6-dihydroxy-2- dimethylaminotetralin (M7), apomorphine and dopamine. J Pharmacol Exp Ther 1975; 192: 336-342.

4. Huang $Y$, Luedtke R, Freeman R, Wu L, Mach R. Synthesis and structure-activity relationships of naphthamides as dopamine $\mathrm{D}_{3}$ receptor ligands. J Med Chem 2001; 44(11): 1815-1826.

5. Sidhu A, Laruelee M, Vernier P. Dopamine Receptors and Transporters: Function, Imaging and Clinical Implication. $2^{\text {nd }}$ Ed USA: Marcel Dekker Inc; 2003, p 1-5.

6. Wieringen J, Booij J, Shalgunov V, Elsinga P, Michel M. Agonist high and low affinity states of dopamine $\mathrm{D}_{2}$ receptors: methods of detection and clinical implications. N-S Arch Pharmacol 2013; 386(2): 135-154.

7. Di Giovanni G, Esposito E, Di Matteo V. Role of serotonin in eentral dopamine dysfunction. CNS Neurosei Ther 2010; 16(3): 179-194.

8. Nichols C. Serotonin, Encyclopedia of the Neurological Sciences, Second edition, 2014; 145-147.

9. Berg KA, Harvey JA, Spampinato U, Clarke WP. Physiological and therapeutic relevance of constitutive activity of $5-\mathrm{HT}_{2 \mathrm{~A}}$ and $5-\mathrm{HT}_{2 \mathrm{C}}$ 
receptors for the treatment of depression. Prog Brain Res 2008; 172:287-305.

10. Volkow ND, Wang GJ, Fowler JS, Tomasi D, Telang F. Addiction: beyond dopamine reward eircuitry. Proc Natl Acad Sei USA 2011;108(37):15037-15042.

11. Rodman MJ. Cómo y Porqué de la Farmacoterapia. $17^{\text {th }}$ Ed. San Bernardino (México DF): Ediciones P.L.M. S.A; 1981, p 33.

12. Goodman A, Rall TW, Nies AS, Taylor P. Las Bases Farmacológicas de la Terapéutica. $8^{\text {th }}$ Ed. México: Editorial Médica Panamericana; 1991, p 458-461.

13. Angel J, Andujar S, Migliore de Angel B, Charris J, Israel A, Suárez-Roca H, López S, Garrido M, Cabrera E, Visbal G, Rosales C, Suvire F, Enriz R. Synthesis, dopaminergic profile and molecular dynamics calculations of N-Aralkyl substituted 2- aminoindans. Bioorg Med Chem 2008; 16: 3233-3244.

14. Brichta L, Greengard P, Flajolet M. Advances in the pharmacological treatment of Parkinson's disease: targeting neurotransmitter systems. Trends Neurosei 2013; 36(9): 543-554.

15. Aono $M$, Iga $J$, Ueno $S$, Agawa $M$, Tsuda $T$, Ohmori T. Neuropsychological and psychiatric assessments following bilateral deep brain simulation of the subthalamic nucleus in Japanese patients with Parkinson's disease. J Clin Neurosei 2014; 21:1595-1598.

16. World Health Organization. Neurological disorders: public health challenges. 2006; Consultado en: [En línea] 2006 [Citado el 14 de enero de 2014] disponible en: https://www.who.int/mental_health/neurology/neurodiso/en/.

17. Hoehn M. The natural history of Parkinson's disease in the pre-levodopa and post-levodopa eras. Neurol Clin 1992; 10: 331-339.

18. Angel J. Diseño y Síntesis de Aminotetralinas y Aminoindanos Rígidos con Posible Actividad Dopaminérgica. [Tesis Doctoral] Caracas: Univ. Central de Venezuela; 1993.

19. Ramírez MM. Síntesis de los derivados de: lilolidina, acenafteno y quinolinas como noveles compuestos con posible actividad dopaminérgica central [Tesis Doctoral] Zulia: Univ. del Zulia; 2014.

20. Orfila L, Angel J, Torres M, Barbella Y, Israel A. Evidence for a dopaminergic involvement in the renal action of centrally administered JA116a, a novel compound with possible dopaminergic activity in rats. J Pharm Pharmacol 1994; 46: 397-399.

21. Pérez J, Pérez $Z$, Angel J, Charris J, Torres $\mathbf{M}$, Israel A. Synthesis of (+)-amino$6,7,8,8^{\text {a }}$-tetrahidroacenaphtene with possible eentral dopaminergic activity. B Chim Farma 1995; 134: 339-332.

22. Charris J, Pérez J, Duerto de Pérez Z, Ayala C, Stern A, Migliore B, Michelena E, Caldera J, Compagnone R, Avila D, Rodríguez L, Angel J. Synthesis of 1-amino$6,7,8,8^{\mathrm{a}}$-tetrahydroacenaphthenes and its effect on the inhibition of the MAO-enzyme at the brain cortex and liver level. Die Pharm 2000; 55: 62-64.

23. Cannon $\mathbf{J}$, Long $\mathbf{J}$, Bhatnagar $\mathbf{R}$. Future directions in dopaminergic nervous system and dopaminergic agonists. J Med Chem 1981; 24(10): 1113-1118.

24. Osamu I, Mitsuru T, Chieko M, Kazunaga F. Studies on absorption, biotransformation and excretion of drug. II. Metabolism of 2-Indamine. Chem Pharm Bull 1972; 20(4): 734-740.

25. Costall B, Naylor RJ, Cannon J G, Lee TJ. Differentiation of the dopamine mechanisms mediating stereotyped behavior and hyperactivity in the nucleus accumbens and caudate-putamen. J Pharm Pharmacol 1977; 29(6): 337-342.

26. Snedecord G, Cochnar W. Statical Methods. Seventh Ed. Iowa State University Press, Amer. 1982. Ser. Printing.

27. Creese L, Iversen SD. The pharmacological and anatomical substrates of the amphetamine response in the rat. Brain Res 1975; 83: 419-436.

28. Chartoff EH, Marck BT, Matsumoto AM, Dorsa DM, Palmiter RD. Induction of stereotypy in dopamine-deficient mice requires striatal D1 receptor activation. Proc Natl Acad Sci USA 2001; 98(18): 10451-10456.

29. Israel A, Torres M, Ciereo M, Barbella Y. Further evidence for a dopaminergic involvement in the renal action of centrally administered atrial natriuretic peptide in rats. Brain Res Bull 1991; 27: 739-742.

30. Murphy S. Comparative assessment of effieacy and withdrawal symptoms after 6 and 12 weeks treatment with diazepam or buspirone. Br J Psychiatry 1985; 154: 529-534. 
31. Perdomo LE, Balza K, Acurero GA, Angel LB, Dabian AS, Faría AR, Linero AR, Zapata MV, Vera M, Mighliore de Angel B, Suárez-Roca $\mathrm{H}$, Israel $\mathrm{A}$, Charris $\mathrm{J}$, López $\mathrm{SE}$, Ramírez MM, Angel JE. Designn, synthesis and preliminary pharmacologic evaluation of 2-aminoindane-quinoline analogs as dopaminergic agents. Der Pharm Chem 2015; 7(5): 130-135.

32. Ferrer RE, Urdaneta NC, Porta N, Rodríguez LCh, Rosales CC, Espinoza GA, Angel LB, Balza K, Perdomo LE, Faría AR, Dabian AS, Zapata MV, Linero AR, Acurero GA, Israel A, Garrido MR, Suárez-Roca H, Miǵliore B, López S E, Charris J, Ramírez MM, Angel JE. Novedosos agentes dopaminérgícos centrales derivados del 2-aminoindano- 4,7 disustituido atípico. Síntesis y perfil farmacológico central. Invest Clin 2015; 56(2): 137-154.

33. Angel LB, Balza K, Perdomo LE, Dabian AS, Faría AR, Linero AR, Migiliore B, Suárez-Roca $\mathrm{H}$, Charris $\mathbf{J}$, Israel $\mathrm{A}$, Ramírez MM, Angel JE. Síntesis y evaluación farmacológica preliminar de nuevos compuestos quinolínicos con actividad anti corea de huntington. Rev Fac Farm 2015; 78 (1-2): 94-100.

34. Andujar S, Garibotto F, Migliore de Angel B, Angel-Guío J, Charris J, Enriz, R. Molecular recognition and binding mechanism of N-aralkyl substituted 2 aminoindans to the dopamine $\mathrm{D}_{2}$ receptor. A theoretical study. J Argent Chem Soc 2006; 94:1-11.

35. Angel J, Santiago A, Rossi R, Migliore B, Barolo S, Andujar S, Hernández V, Rosales C, Charris J E, Suarez-Roca H, Israel A, Ramírez MM, Ortega J, Herrera Cano N, Enriz RD. Synthesis and preliminary pharmacological evaluation of methoxilated indoles with possible dopaminergic central action. Lat Am J Pharm 2011; 30 (10): 1934-1942.

36. Seeger TF, Seymour PA, Schmidt AW, Zorn SH, Schulz DW, Lebel LA, McLean S, Guanowsky V, Howard HR, Lowe JA. Ziprasidone (CP-88,059): A new antipsychotic with combined dopamine and serotonin receptor antagonist activity. J Pharmacol Exp Ther 1995; 275: 101-113.
37. Lucas G, De Deurwaerdère P, Caccia $S$, Spampinato $\mathbf{U}$. The effect of serotonergic agents on haloperidol-induced striatal dopamine release in vivo: opposite role of 5-HT(2A) and 5-HT(2C) receptor subtypes and significance of the haloperidol dose used. Neuropharmacology 2000;39(6):1053-1963.

38. Simola N, Morelli M, Carta AR. The 6-hydroxydopamine model of Parkinson's disease. Neurotox Res 2007; 1:151-167.

39. Thoenen H, Tranzer JP. Chemical sympathectomy by selective destruction of adrenergic nerve endings with 6-Hydroxydopamine. N-S Arch Ex Path Ph 1968; 261: 271-288.

40. Jeon B, Jackson-Lewis SV, Burke RE. 6-Hydroxydopamine lesion of the rat substantia nigra: time course and morphology of cell death. Neurodegeneration 1995; $4: 131-137$.

41. Ungerstedt. U. 6-Hydroxy-dopamine indueed degeneration of central monoamine neurons. Eur J Pharmacol 1968; 5: 107 110.

42. Meltzer HY. Serotonergic mechanisms as targets for existing and novel antipsychotics. Curr Antipsy Hand Exp Pharmacol 2012; 212: 87-124.

43. Ushijima I, Carino M, Horita A. Involvement of D1 and D2 dopamine systems in the behavioral effects of cocaine in rats. Pharmacol Biochem Behav 1995; 52: 737-741.

44. Molloy AG, Waddington JL. Dopaminergic behavior stereospecifically promoted by the $\mathrm{D}_{1}$ agonist R-SK \& F38393 and selectively blocked by the $\mathrm{D}_{1}$ antagonist SCH 23390 . Psychopharmacology 1984; 82(4): 409-410.

45. Nichols DE. The development of novel dopamine agonists in: Kaiser C, Kebabian J W. (eds) Dopamine Receptors ACS Symposium Ser. 224. Cap 9 Washington, DC 1983; 201218. 